\title{
Infectious Etiology of Acute Respiratory Distress Syndrome (ARDS) with Thrombocytopenia in Adults and their Antimicrobial Sensitivity Pattern
}

\author{
Pritam J. Pardeshi*, Anuradha S. De and Sujata M. Baveja \\ Department of Microbiology, L.T.M. Medical College \& Hospital, Mumbai, India \\ *Corresponding author
}

\begin{abstract}
A B S T R A C T
Keywords

Acute Respiratory

Distress Syndrome

(ARDS) with

thrombocytopenia;

Infectious etiology;

Antimicrobial

susceptibility

(ABS) pattern.

\section{Article Info}

Accepted:

22 March 2016

Available Online:

10 April 2016

Acute respiratory distress syndrome (ARDS) manifests as rapidly progressive dyspnea, tachypnea and hypoxemia. Diagnostic criteria include acute onset, profound hypoxemia, bilateral pulmonary infiltrates, and the absence of left atrial hypertension. To study the infective organisms and their antimicrobial susceptibility pattern among organisms isolated from Endo-tracheal (ET) aspirates in adult patients admitted to this hospital with ARDS and having thrombocytopenia. In this prospective study, 100 patients above 18 years, admitted in Intensive care Units and on ventilator in a tertiary care hospital were enrolled. Endotracheal secretion culture \& blood culture were performed in all these patients. Out of total 100 patients, Endotracheal secretion culture positive was 76\% and 35\% was blood culture positive. In ET aspirates, Acinetobacter species was commonest (43.37\%), followed by Klebsiella pneumoniae (18.07\%) and Pseudomonas aeruginosa (16.86\%). Overall susceptibility to amikacin was $24.4 \%$ and to cephalosporins was $<2 \%$. Susceptibility to imipenem was $89.3 \%$. Overall carbapenem resistance was $10.7 \%$. The need for diagnostic testing to determine the etiology of ARDS is essential so that management of patients with ARDS can be instituted promptly.
\end{abstract}

\section{Introduction}

ARDS, the most severe form of acute lung injury (ALI), is caused several direct injuries like Community Acquired Pneumonia (CAP), aspiration and indirect injuries to the lungs like sepsis, tropical illnesses etc. ARDS usually requires mechanical ventilation and admission to an intensive care unit (ICU). ARDS is also a major cause of ICU morbidity and mortality worldwide (Wang et al., 2014). Infectious etiology of ARDS is Gram-negative bacteria like Acinetobacter species, Klebsiella pneumoniae are commoly isolated, followed by Pseudomonas aeruginosa,Escherichia coli,Enterobacter cloacae, Gram-positive bacteria like Methicillin Resistant Staphylococcus aureus (Bauer et al., 2006).

Since recognition of ARDS in 1967, a lot of clinical studies and trials have been conducted in the field of ARDS (Bernard et $a l ., 2005)$. There are studies on incidence, outcome, etiology, treatment and ventilator strategies of ARDS but there is no 
documented study on ARDS patients with thrombocytopenia. This study attempts to find out the infective organisms and their antimicrobial susceptibility pattern isolated from Endotracheal (ET) aspirates of adult ARDS patients with thrombocytopenia admitted in Intensive Care Units (ICU) of this hospital.

\section{Materials and Methods}

This is a prospective study enrolling 100 consecutive cases of ARDS with thrombocytopenia admitted to Medical Intensive Care Unit (MICU) and Intensive Respiratory Care Unit (IRCU) of a tertiary care hospital over a period of one year in 2013. Institutional Ethical Committee approval was obtained prior to commencement of the study.

Patients with ARDS were identified through a prospective daily ICU surveillance, based on the American-European Consensus Conference (AECC) criteria:

\section{Acute onset}

Ratio of partial pressure of arterial oxygen to fraction of inspired oxygen $\left(\mathrm{PaO}_{2} / \mathrm{FiO}_{2}\right)$ of 200 or less, regardless of positive endexpiratory pressure

Bilateral infiltrates seen on frontal chest radiograph and pulmonary artery wedge pressure of $18 \mathrm{~mm} \mathrm{Hg}$ or less when measured, or no clinical evidence of left atrial hypertension (Saguil et al., 2012)

All adult patients with ARDS with thrombocytopenia admitted in ICUs were included in this study and patients with chronic obstructive pulmonary disease, HIV seropositive, with cardiac failure and age below 12 years were excluded.
Statistical analysis was performed using computer based program SPSS version 15. Student $t$-test was performed for continuous variables. $P$ value $<0.05$ was considered to be statistically significant.

Patients were sedated with midazolam or fentanyl and oxygen saturation was monitored during the procedure of collection of ET secretion. A tracheal aspiration (TA) tube was inserted approximately $24 \mathrm{~cm}$ into the trachea and the sample fluid (ET secretion) was aspirated into a polypropylene tube and collected in a sterile container. If there was no fluid production during the procedure, $5 \mathrm{~mL}$ of saline solution was injected and rapidly aspirated (Kirtland et al., 1997).

Gram stain was done, followed by plating on blood agar, chocolate agar and MacConkey agar and all the plates were incubated at $37^{\circ} \mathrm{C}$ for 24 hours. Chocolate agar was kept in candle jar. Next day, growth of even single colony was processed and organisms were identified by standard biochemical tests. Antibiotic susceptibility testing was done on Muller Hinton agar by Kirby Bauer Disc Diffusion Method (KBDDM), according to CLSI guidelines (Paimer et al., 1995) (Slagle et al., 1989).

For collection of blood culture sample, a tourniquet was applied and a suitable vein was selected. The venepuncture site was cleansed with $70 \%$ alcohol, followed by $2 \%$ tincture of iodine/ chlorhexidine Disinfectant was allowed to dry before blood was aspirated. Minimum of $10 \mathrm{ml}$ blood was collected and inoculated into blood culture bottle containing tryptic soy broth. The bottles were incubated at $37^{\circ} \mathrm{C}$ for 7 days. Each bottle was examined daily for macroscopic evidence of microbial growth. Total three subcultures were done on blood agar and MacConkey agar plates, 
i.e. on $2^{\text {nd }}$ day, $4^{\text {th }}$ day and $7^{\text {th }}$ day. Any growth from one of the subcultures was identified by standard biochemical tests.If no growth was seen up to third subculture, the bottle was finally discarded (Ntusi $\mathrm{N}$ et al., 2010).

\section{Results and Discussion}

The incidence of ARDS with thrombocytopenia in ICUs during the study period of one year was $10.26 \%$. ARDS was more common in patients who were aged $>60$ years $(32 \%)$ and in males $(60 \%)$. The mortality rate was high among them.

Maximum ET secretions were purulent (71\%) followed by mucoid (17\%) and mucopurulent (12\%). In Gram stain of ET secretion culture, $66 \%$ showed pus cells and Gram negative bacilli/ coccobacilli; 3\% showed pus cells and Gram positive cocci; $2 \%$ showed pus cells, Gram negative bacilli Gram negative coccobacilli; whereas $29 \%$ showed pus cells and no organisms.

Out of 100ET secretions, culture was positive in $76 \%$, of which $96.06 \%$ were Gram negative bacilli and $03.94 \%$ were gram positive cocci. Organisms isolated from ET secretions shown in Table 1. Commonest organism isolated was Acinetobacter species (43.37\%), followed by Klebsiella pneumoniae (18.07\%) and Pseudomonas aeruginosa (16.86\%).

Maximum ET secretions showed single growth $(90.78 \%)$.

Comparison of ARDS patients with growth and no growth in ET secretions was done.

Age and platelet count were significantly lower in patients showing no growth in ET secretions, whereas $\mathrm{PaO}_{2} / \mathrm{FiO}_{2}$ was significantly lower in patients showing growth in ET secretion (Table 2).

In blood cultures of these 100 patients, 35\% showed growth, of which $91.43 \%$ were Gram negative bacilli and $08.57 \%$ were Gram positive cocci. The organisms isolated from blood cultures are shown in Table 3. Commonest organism isolated was also Acinetobacter species (34.28\%). All blood culture samples showed single growth.

On comparison of growth of bacteria in blood cultures and ET secretion cultures in 100 cases, in $34 \%$ cases, both ET and blood cultures were positive, whereas in $42 \%$ of cases only ET culture was positive (Barr Diagram1).

In isolates from ET secretions, overall susceptibility to amikacin was $24.4 \%$ and to cephalosporins was $<2 \%$. Susceptibility to imipenem was $89.3 \%$, followed by $51.5 \%$ susceptibility to netilmycin. Overall carbapenem resistance was $10.7 \%$. Other Gram negative bacilli showed less than $17 \%$ susceptibility to all first line antibiotics (Tables 4 \& 5). Five carbapenem resistant Acinetobacter spp. were susceptible to tigecycline, colistin and two carbapenem resistant Enterobacter spp. was susceptible to tigecycline. None of the isolates were Extended Spectrum Beta-lactamase (ESBL) producers.

Both MRSA isolated was susceptible to vancomycin and linezolid.Single MSSA isolated was susceptible to co-trimoxazole and ciprofloxacin. No Vancomycin Intermediate Staphylococcus aureus (VISA), Vancomycin Resistant Staphylococcus aureus (VRSA) or Vancomycin Resistant Enterococci (VRE) was detected.

A total of 100 patients were enrolled in this study. The incidence of ARDS with thrombocytopenia in ICUs during the study 
period of one year was $10.26 \%$ (100/974). A study from India showed incidence of ARDS in ICUs as 10\%, which is almost similar to the present study (Sachdev SPS et al., 2014). Maximum number of cases of ARDS was seen in the age group of $>60$ years (32\%). Studies from America and Washington and have stressed that incidence of ARDS increases with age (http://emedicine.medscape.com/article/165 139-overview\#showall) (Rubenfeld GD et al., 2005).

In ARDS patients, ET secretion culture is indicated, as it is a lower respiratory tract sample and therefore, is less likely to be contaminated by oropharyngeal colonizers (Mandell LA et al. 2007)In this study, $76 \%$ of ET secretions showed growth and 24\% showed no growth in culture. Study by Shanmuga et al. (2014) showed growth in $73 \%$ and Anushan et al. (2014) showed growth in $75 \%$ of ET secretion cultures, which are almost similar to the present study. In this study, gram negative bacilli $(96.06 \%)$ were most commonly isolated from ET secretions. Study by Shanmuga et al. (2014) and Anushan et al. (2014) also showed predominance of gram negative bacilli in $92 \%$ and $94.2 \%$ respectively.

Commonest organisms isolated from ET cultures in the present study were Acinetobacter spp. (43.37\%), followed by Klebsiella pneumoniae (18.07\%) (Table1). Study by George et al (2010) and Abdollahi et al (2013) also showed Acinetobacter sp. (37.5\% and $24.2 \%$ respectively) as the commonest organism from ET secretions. In a study by Vigg et al. (2003) from hederabad, commonest organisms isolated from ET culture in ARDS patients was Pseudomonas aeruginosa, followed by Klebsiella species. Studies from India by Shanmuga et al. (2014) and Anushan et al. (2014), showed that most common organism isolated from ET cultures to be Klebsiella pneumoniae (36\% and $38.5 \%$ respectively).

In the present study, $35 \%$ of blood culture samples showed growth and $91.43 \%$ of them were gram negative bacilli. Blood cultures are optional for all hospitalized patients with ARDS, though yield of blood cultures is relatively low (Mandell LA et al., 2007). Commonest organisms isolated from blood cultures were Acinetobacter spp. (34.28\%), followed by Klebsiella pneumoniae (20\%) (Table 3). Study by Vigg et al., (2003) showed Pseudomonas aeruginosa to be the commonest $(42 \%)$, followed by Klebsiella species (28\%), isolated from blood cultures in ARDS patients.

In this study, 34\% of patients showed growth, both in ET secretions and blood cultures and $42 \%$ of patients showed growth only in ET culture. Growth in ET secretion was mostly seen in direct causes and in some cases of acute febrile illness, whereas growth in both ET secretion and blood culture was seen mostly in indirect causes. One patient had growth in blood culture but not in ET secretion. This was a case of urinary tract infection (UTI) and Escherichia coli was grown both from blood culture and urine culture (Bar Diagram 1). Study from Gujarat ET secretion positive in $85 \%$ and blood culture in $38 \%$ of patients (Modi P et al., 2011).

On comparing the two categories of "growth" and "no growth" in 100 cases of ARDS, mean age and mean platelet count was significantly lower in patients with no growth (39.33 years and 42.75 thousand /cu.mm respectively) in ET secretions as compared to growth (48.72 years and 64.99 thousand /cu.mm respectively) (Table 2). Possible explanation is that ARDS caused due to tropical illnesses like malaria, dengue, leptospirosis, etc., which is very prevalent in Indian scenario, will have very low platelet count due to the tropical illness 
and might not show any growth in ET secretion culture. Mean $\mathrm{PaO}_{2} / \mathrm{FiO}_{2}$ ratio was significantly low in growth (147.09), than no growth (165.88). This can be explained as most patients showing growth in ET secretions were suffering from direct causes like Community Acquired Pneumonia (CAP), aspiration, etc. All the other parameters were not significant.

Table.1 Organisms Grown from ET Secretion Cultures in 76 Cases

\begin{tabular}{|l|c|c|}
\hline \multicolumn{1}{|c|}{ Bacteria } & No. & \% \\
\hline Acinetobacter species & 36 & 43.37 \\
\hline Klebsiella pneumoniae & 15 & 18.07 \\
\hline Pseudomonas aeruginosa & 14 & 16.86 \\
\hline Escherichia coli & 09 & 10.84 \\
\hline Enterobacter species & 06 & 07.22 \\
\hline Methicillin resistant Staphylococcus aureus (MRSA) & 02 & 02.40 \\
\hline Methicillin sensitive Staphylococcus aureus (MSSA) & 01 & 01.20 \\
\hline Total & $\mathbf{8 3}$ & $\mathbf{1 0 0}$ \\
\hline
\end{tabular}

Table.2 Comparison of ARDS Patients with Growth and No Growth in ET Secretions

\begin{tabular}{|l|l|l|l|l|}
\hline \multicolumn{1}{|c|}{ Parameters } & \multicolumn{1}{|c|}{$\begin{array}{c}\text { Growth (76) } \\
\text { Mean }( \pm \text { SD) }\end{array}$} & $\begin{array}{c}\text { No growth (24) } \\
\text { Mean }( \pm \text { SD) }\end{array}$ & $\begin{array}{c}\text { P } \\
\text { value }\end{array}$ & \multicolumn{1}{|c|}{ Significance } \\
\hline Age (years) & $48.72( \pm 16.868)$ & $39.33( \pm 16.521)$ & 0.019 & Significant \\
\hline $\mathrm{Hb}(\mathrm{gm} / \mathrm{dl})$ & $7.82( \pm 1.186)$ & $7.92( \pm 1.157)$ & 0.719 & NS \\
\hline $\begin{array}{l}\text { Platelet }(/ \mathrm{cu} . \mathrm{mm} \text { in } \\
\text { thousands })\end{array}$ & $64.99( \pm 24.968)$ & $42.75( \pm 27.235)$ & 0.000 & Significant \\
\hline $\mathrm{PCO}_{2}(\mathrm{mmHg})$ & $51.51( \pm 12.618)$ & $49.63( \pm 12.479)$ & 0.523 & NS \\
\hline $\mathrm{PaO}_{2}(\mathrm{mmHg})$ & $84.61( \pm 48.756)$ & $85.00( \pm 12.148)$ & 0.906 & NS \\
\hline $\mathrm{PaO}_{2} / \mathrm{FiO}$ & $147.09( \pm 34.273)$ & $165.88( \pm 34.893)$ & 0.022 & Significant \\
\hline $\mathrm{Hospital}_{2}$ stay (days) & $15.47( \pm 6.094)$ & $14.88( \pm 3.904)$ & 0.652 & NS \\
\hline
\end{tabular}

Table.3 Organisms Grown from Blood Cultures in 35 Cases

\begin{tabular}{|l|c|c|}
\hline \multicolumn{1}{|c|}{ Organism } & No. & \% \\
\hline Acinobacter species & 12 & 34.28 \\
\hline Klebsiella pneumonae & 07 & 20.00 \\
\hline Pseudomonas aeruginosa & 04 & 11.42 \\
\hline Escherichia coli & 07 & 20.00 \\
\hline Enterobacter species & 03 & 08.57 \\
\hline Methicillin resistant Staphylococcus aureus (MRSA) & 02 & 05.71 \\
\hline Methicillin sensitive Staphylococcus aureus (MSSA) & 01 & 02.85 \\
\hline Total & $\mathbf{3 5}$ & $\mathbf{1 0 0}$ \\
\hline
\end{tabular}


Table.4 Antimicrobial Susceptibility (ABS) Pattern of Gram Negative Bacilli Isolated from ET Secretions

\begin{tabular}{|c|c|c|c|c|c|c|c|c|c|c|c|}
\hline \multirow{2}{*}{$\begin{array}{l}\text { Gram negative } \\
\text { bacilli (No.) }\end{array}$} & AK & CIP & $\begin{array}{l}\mathbf{A M} \\
\mathbf{C}\end{array}$ & CTX & $\begin{array}{l}\mathrm{CX} \\
\mathbf{M}\end{array}$ & PI & IPM & PIT & NET & CPM & CIS \\
\hline & $\begin{array}{l}\text { No. } \\
(\%)\end{array}$ & $\begin{array}{l}\text { No. } \\
(\%)\end{array}$ & $\begin{array}{l}\text { No. } \\
(\%)\end{array}$ & $\begin{array}{l}\text { No. } \\
(\%)\end{array}$ & $\begin{array}{l}\text { No. } \\
(\%)\end{array}$ & $\begin{array}{l}\text { No. } \\
(\%)\end{array}$ & $\begin{array}{l}\text { No. } \\
(\%)\end{array}$ & $\begin{array}{l}\text { No. } \\
(\%)\end{array}$ & $\begin{array}{l}\text { No. } \\
(\%)\end{array}$ & $\begin{array}{l}\text { No. } \\
(\%)\end{array}$ & $\begin{array}{l}\text { No. } \\
(\%)\end{array}$ \\
\hline $\begin{array}{l}\text { Acinetobacter } \\
\text { species }(36)\end{array}$ & $\begin{array}{l}04 \\
(11.1)\end{array}$ & $\begin{array}{l}03 \\
(8.3)\end{array}$ & $\begin{array}{l}02 \\
(5.5)\end{array}$ & $\begin{array}{l}01 \\
(2.7)\end{array}$ & $\begin{array}{l}00 \\
(00)\end{array}$ & $\begin{array}{l}00 \\
(00)\end{array}$ & $\begin{array}{l}31 \\
(86.1)\end{array}$ & $\begin{array}{l}6 \\
(16.6)\end{array}$ & $\begin{array}{l}13 \\
(36.1)\end{array}$ & $\begin{array}{l}2 \\
(5.5)\end{array}$ & $\begin{array}{l}00 \\
(00)\end{array}$ \\
\hline $\begin{array}{l}\text { Klebsiella } \\
\text { pneumoniae(15) }\end{array}$ & $\begin{array}{l}10 \\
(66.6)\end{array}$ & $\begin{array}{l}03 \\
(20)\end{array}$ & $\begin{array}{l}00 \\
(00)\end{array}$ & $\begin{array}{l}00 \\
(00)\end{array}$ & $\begin{array}{l}00 \\
(00)\end{array}$ & $\begin{array}{l}01 \\
(6.6)\end{array}$ & $\begin{array}{l}15 \\
(100)\end{array}$ & $\begin{array}{l}4 \\
(26.6)\end{array}$ & $\begin{array}{l}13 \\
(86.6)\end{array}$ & $\begin{array}{r}00 \\
(00)\end{array}$ & $\begin{array}{l}02 \\
(13.3)\end{array}$ \\
\hline $\begin{array}{l}\text { Escherichia coli } \\
\text { (09) }\end{array}$ & $\begin{array}{l}05 \\
(55.5)\end{array}$ & $\begin{array}{l}01 \\
(11.1)\end{array}$ & $\begin{array}{l}00 \\
(00)\end{array}$ & $\begin{array}{l}00 \\
(00)\end{array}$ & $\begin{array}{l}00 \\
(00)\end{array}$ & $\begin{array}{l}00 \\
(00)\end{array}$ & $\begin{array}{l}9 \\
(100)\end{array}$ & $\begin{array}{l}7 \\
(77.7)\end{array}$ & $\begin{array}{l}6 \\
(66.6)\end{array}$ & $\begin{array}{l}00 \\
(00)\end{array}$ & $\begin{array}{l}00 \\
(00)\end{array}$ \\
\hline $\begin{array}{l}\text { Enterobacter } \\
\text { species }(6)\end{array}$ & $\begin{array}{l}01 \\
(16.6)\end{array}$ & $\begin{array}{l}00 \\
(00)\end{array}$ & $\begin{array}{l}00 \\
(00)\end{array}$ & $\begin{array}{l}00 \\
(00)\end{array}$ & $\begin{array}{l}00 \\
(00)\end{array}$ & $\begin{array}{l}00 \\
(00)\end{array}$ & $\begin{array}{l}4 \\
(66.6)\end{array}$ & $\begin{array}{l}3 \\
(50)\end{array}$ & $\begin{array}{l}2 \\
(33.3)\end{array}$ & $\begin{array}{l}00 \\
(00)\end{array}$ & $\begin{array}{l}00 \\
(00)\end{array}$ \\
\hline Total (66) & $\begin{array}{l}16 \\
(24.2)\end{array}$ & $\begin{array}{l}07 \\
(10.6)\end{array}$ & $\begin{array}{l}02 \\
(3.0)\end{array}$ & $\begin{array}{l}01 \\
(1.5)\end{array}$ & $\begin{array}{l}00 \\
(00)\end{array}$ & $\begin{array}{l}01 \\
(1.5)\end{array}$ & $\begin{array}{l}59 \\
(89.3)\end{array}$ & $\begin{array}{l}20 \\
(30.3)\end{array}$ & $\begin{array}{l}34 \\
(51.5)\end{array}$ & $\begin{array}{l}02 \\
(3.0)\end{array}$ & $\begin{array}{l}02 \\
(3.0)\end{array}$ \\
\hline
\end{tabular}

AK - Amikacin; I - Imipenem; CIP- Ciprofloxacin; PT- Piperacillin-Tazobactam;

AMC - Amoxycillin-Clavulinic acid; NT- Netilmicin; CTX - Cefotaxime; CPM- Cefepime; CXM- Cefuroxime; CIS- CefoperazoneSulbactum; PI - Piperacillin.

Bar diagram.1 ABS Pattern of Gram Negative Bacilli Isolated from ET Secretions

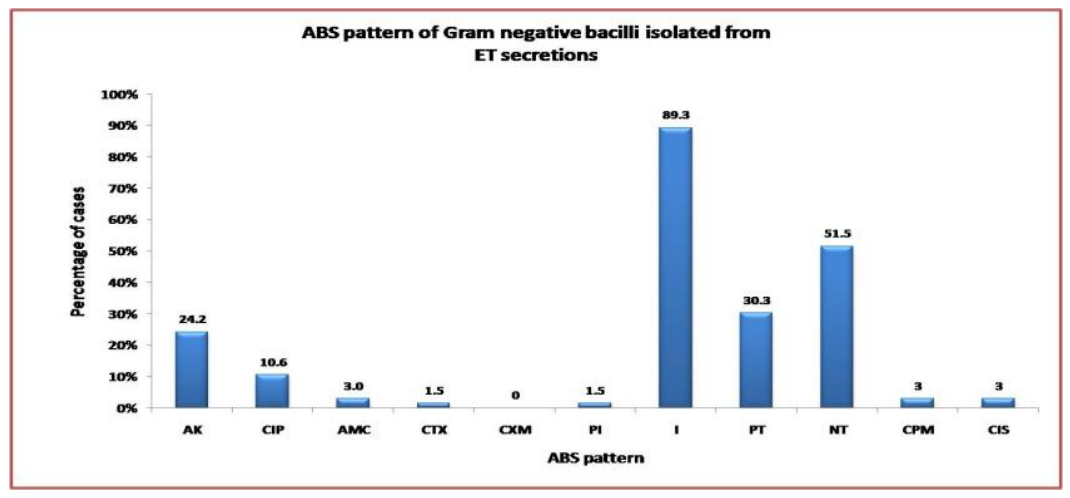

Bar diagram.2 ABS Pattern of Pseudomonas aeruginosa Isolated in ET Secretion

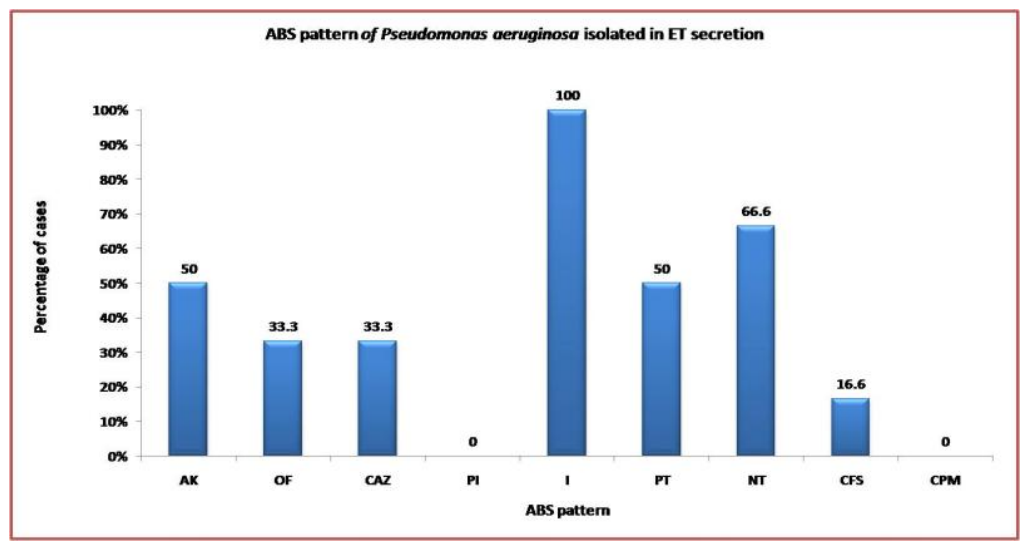

CFS- Cefoperazone sulbactum; Pseudomonas aeruginosa showed $100 \%$ susceptibility to Imipenem 


\section{Bar diagram.3 Comparison of Growth of Bacteria in Blood Culture and ET Secretion Culture}

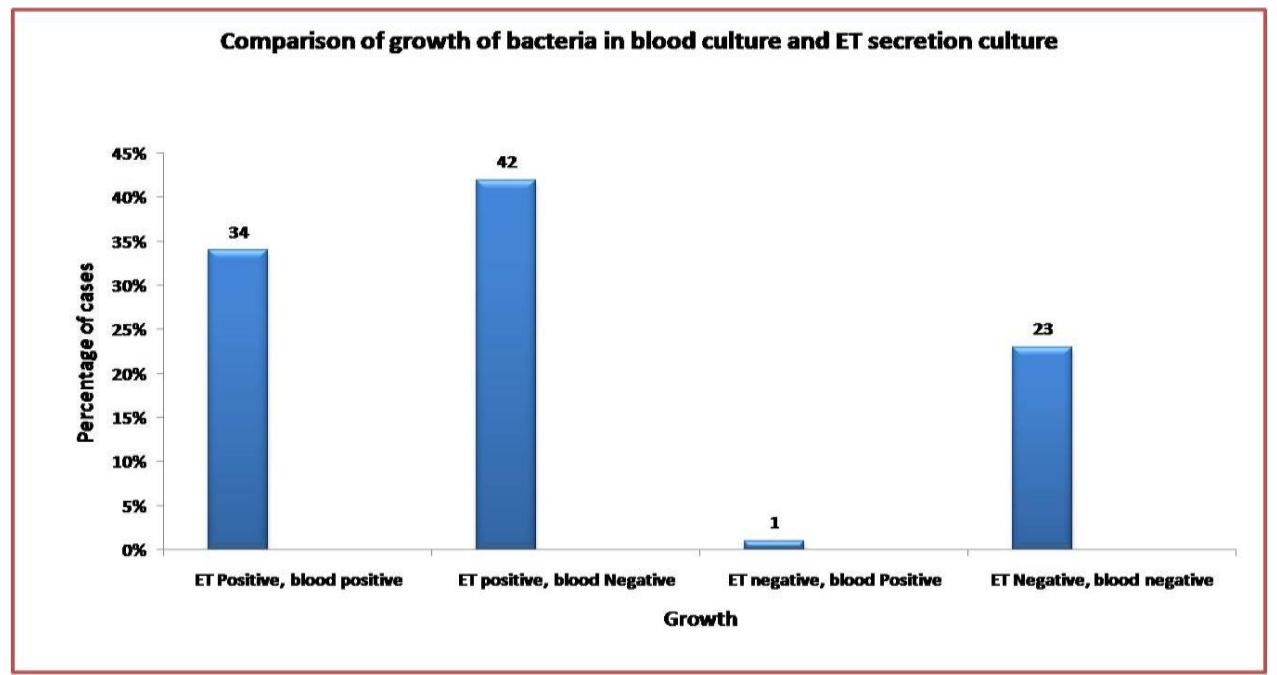

In the present study, antibiotic susceptibility of the organisms isolated from ET secretions were tested. Amikacin susceptibility of Klebsiella pneumoniae was66.6\%, followed by Escherichia coli (55.5\%) (Tables 4 \& Bar diagram 3). Susceptibility of Acinetobacter spp. to ciprofloxacin, cefotaxime, imipenem, cefepime, netilmycin and piperacillintazobactam was $8.3 \%, 2.7 \%, 86.1 \%, 5.5 \%$, $36.1 \%$ and $16.6 \%$ respectively(Table 4$)$. A study by Abdollahi et al (2013) showed susceptibility of Acinetobacter spp. to ciprofloxacin, cefotaxime, imipenem and cefepime to be $12 \%, 2.6 \%, 92.6 \% \%$ and $0 \%$ respectively in ET secretions. One Indian study reported Acinetobacter spp. susceptible to ciprofloxacin, cefotaxime, imipenem, netilmycin and piperacillintazobactam as $28 \%, 10 \%, 100 \%, 14 \%$ and $21 \%$ respectively in ET secretions (Modi PP 2012). Vadivoo NS et al (2014) also showed good susceptibility of Acinetobacter spp. to imipenem (94\%).

In this study, Klebsiella pneumonia susceptibility to ciprofloxacin, cefotaxime, imipenem, netilmycin and piperacillintazobactam was $20 \%, 0 \%, 100 \%, 86.6 \%$ and $26.6 \%$ respectively (Table 4 ). One Indian study showed Klebsiella pneumonia susceptibility to the above 5 antibiotics to be $47 \%, 18 \%, 93 \%, 40 \%$ and $38 \%$ respectively (Modi PP et al 2012). A study by Abdollahi et al (2013) showed Klebsiella pneumoniae susceptibility to ciprofloxacin, cefotaxime, imipenem and cefepime as 76.66\%, $14.3 \%$, $98.2 \%$ and $25 \%$ respectively.

In this study, Pseudomonas aeruginosa susceptibility to amikacin, ofloxacin, ceftazidime, piperacillin, imipenem and piperacillin-tazobactam was $50 \%, 33.3 \%$, $33.3 \%, 0 \%, 100 \%$ and $50 \%$ respectively(Bar diagram 3). A study by Modi et al (2012) showed susceptibility to all the above 6 antibiotics to be $78 \%, 43 \%, 43 \%, 43 \%, 86 \%$ and $43 \%$ respectively.

Overall carbapenem resistance in this study was $10.7 \%$ (Table 4).

ARDS is significantly associated with ESBL producing organisms (Graffunder EM et al., 2005), though in the present study, none of the isolates were Extended spectrum betalactamase (ESBL) producer.

The use of appropriate antibiotics which are 
directed towards the most prevalent organisms improves the cure rate and survival and also reduces the emergence of resistant strains. A local antibiogram for each hospital, based on bacteriological patterns and susceptibilities is essential to initiate empiric therapy, to prevent poor outcomes and help in framing the appropriate institutional antibiotic policy (Anusha N et al., 2014).

In conclusion, all patients with ARDS should be investigated for specific pathogens that would significantly alter standard management decisions. The need for diagnostic testing to determine the etiology of ARDS is essential so that management of these patients can be instituted promptly.

Increased mortality and increased risk of clinical failure in ARDS patients are more common with inappropriate antibiotic therapy. De-escalation or narrowing of empirical antibiotic therapy on the basis of antibiotic susceptibility testing is likely to decrease an individual's risk of death and also decrease cost and antibiotic resistance pressure.

\section{References}

Abdollahi, A., Shoar, S., Shoar, N. 2013. Microorganisms' colonization and their antibiotic resistance pattern in oro - Tracheal tube. Iran J. Microbiol., 5: $102-7$.

Anusha, N., Madhu, K.B., Arun, B.V. 2014. Microbiological profile and sensitivity pattern of endotracheal secretions in mechanically ventilated. J. Evid. Based Med. Healthcare, 1: 1177-84.

Bauer, T.T., Ewig, S., Rodloff, A.C., Mu, E.E. 2006. Acute Respiratory Distress Syndrome and Pneumonia: A
Comprehensive Review of Clinical Data. Clin. Infect. Dis., 43: 748-55.

Bernard, G.R. 2005. Acute respiratory distress syndrome: a historical perspective. Am. J. Respir. Crit. Care Med., 172: 798-806.

George, P., Sequiera, A. 2010. Antimicrobial sensitivity pattern among organisms which were isolated from the endotracheal aspirates of patients with ventilator associated pneumonia. J. Clin. Diag. Res., 4: 3397-3401.

Graffunder, E.M., Preston, K.E., Evans, A.M., Venezia, R.A. 2005. Risk factors associated with extendedspectrum beta-lactamase-producing organisms at a tertiary care hospital. $J$. Antimicrob. Chemother., 56: 139-45.

http://emedicine.medscape.com/article/1651

39-overview\#showall. Accessed on 22/06/2014.

Kirtland, S.H., Corley, D.E., Winterbauer, R.H., Springmeyer, S.C., Casey, K.R., Hampson, N.B., et al. 1997. The Diagnosis of Ventilator- Associated Pneumonia. Chest, 112: 445-57.

Mandell, L.A., Wunderink, R.G., Anzuetlett, J.G., Campbell, G.D., Dean, N.C., et al. 2007. Infectious Diseases Society of America / American Thoracic Society Consensus Guidelines on the Management of Community-Acquired Pneumonia in Adults. Clin. Infect. Dis., 44: 27-72.

Modi, P., Javadekar, T., Javadekar, B. 2011. Development of bacteremia in ventilator associated pnuemonia patients at a tertiary care hospital, Gujarat - A prospective study. Natl. J. Med. Res., 1: 23-6.

Modi, P.P., Jawedekar, B.T., Sandeep, N., Pandya, N.N. 2012. A study on ventilator associated pneumonia in pediatric age group in a tertiary care 
hospital, Vadodara, Natl. J. Med. Res., 2: 3-6.

Ntusi, N., Aubin, L., Oliver, S., Whitelaw, A., Mendelson, M. 2010. Guideline for the optimal use of blood cultures. S. Afr. Med. J., 100: 839-43.

Paimer, B.L., Smaldone, G.C., Simon, S., Riordan, M.L. 1995. Tracheal Aspirate in Long-term Aspirates Mechanically Ventilated Patients. Chest, 108: 132632.

Rubenfeld, G.D., Caldwell, E., Peabody, E., Weaver, J., Martin, D.P., Neff, M., et al. 2005. Incidence and outcomes of acute lung injury. N. Engl. J. Med., 353: 1685-93.

Saguil, A., Fargo, M. 2012. Acute respiratory distress syndrome: diagnosis and management. Amer. Family Physician, 85: 350-8.

Slagle, T.A., Bifano, E.M., Wolf, J.W., Gross, S.J. 1989. Routine endotracheal cultures for the prediction of sepsis in ventilated babies. Arch. Dis. Child, 64: 34-8.

Sachdev, S.P.S. 2014. Acute Respiratory Distress Syndrome: An Autopsy Study. J. Postgr. Med. Edu. Res., 48: 8-13.

Vigg, A., Mantri, S., Vigg, A. 2003. Clinical profile of ARDS. J. Assoc. Physicians India, 51: 855-8.

Vadivoo, N.S., Santharam, P., Sudha, K., Kalaiselvi, G., Usha, B., Kumar, A., et al. 2014. Dynamic bacterial profile of endotracheal aspirates and its sensitivity pattern - a cause of concern. Int. J. Cur. Res. Rev., 6: 1129.

Wang, T., Liu, Z., Wang, Z., Duan, M., Li, G., Wang, S. 2014. Thrombocytopenia is associated with acute respiratory distress syndrome mortality: An international study. PLoS One, 9: 110.

\section{How to cite this article:}

Pritam J. Pardeshi, Anuradha S. De and Sujata M. Baveja. 2016. Infectious Etiology of Acute Respiratory Distress Syndrome (ARDS) with Thrombocytopenia in Adults and their Antimicrobial Sensitivity Pattern. Int.J.Curr.Microbiol.App.Sci.5(4): 741-749.

doi: http://dx.doi.org/10.20546/ijcmas.2016.504.085 